\title{
Social Capital and Successful Aging: The Role of Senior Housing
}

Carolyn Cannuscio, ScD; Jason Block, MD, MPH; and Ichiro Kawachi, MD, PhD

Social capital is defined as the resources available to individuals and groups through social connections and social relations with others. Access to social capital enables older citizens to maintain productive, independent, and fulfilling lives. As the U.S. population ages, accompanied by a rise in the prevalence of seniors living alone, the availability of social capital within communities will become an important ingredient of successful aging. Recent evidence suggests that many traditional forms of social capital in communities-as represented by civic engagement in local associations and by the extent of voluntarism and social trust-are on the decline. If this observation in correct, there is no simple solution to rebuilding this lost social capital. Novel forms of senior housing, such as planned care developments and assisted-living facilities, may offer promising modes of delivery of social capital to the aging population. However, assisted living remains financially inaccessible for a large segment of the U.S. population, so investment in communities "aging in place" may be the key to delivering the health dividends of social capital.

Ann Intern Med. 2003;139:395-399.

www.annals.org

For author affiliations, see end of text.
$\mathbf{S}$ ocial capital can be defined broadly as the resources available to individuals and groups through their social connections to their communities (1). Although the precise definition of social capital is contested and continues to evolve, most definitions emphasize its characteristic as a collective good (1). Social capital can be considered a kind of public good that is provided by a group or community, and, consequently, the benefits of social capital tend to be more widely shared by members of the community. It is the collective dimension of social capital that most sharply distinguished it from other existing concepts, such as social networks and social support. A classic example of this distinction, which we develop further in the following case study, is the individual who may lack social ties and social support on a personal level but nevertheless benefits from residing within a community that is rich in social connections. In turn, communities with high stocks of social capital may be more effective in responding to external health threats, such as natural disasters, or the threatened closure of local health services. Such communities are also better equipped to protect the health of its citizens, even those who are socially isolated. The social connections that exist within a community therefore represent a form of capital that can be leveraged for health gain (1).

Empirical work has usually measured social capital by proxy indicators, such as the extent of civic engagement within a community (for example, the density of membership of civic organizations), the extent of citizens' participation in voluntary activities, and the levels of trust and norms of mutual aid between members of a community (1).

Social capital is relevant to successful aging in two ways: 1) Older individuals are at greater risk for losing critical parts of their social ties as they age, which makes them more dependent on social capital available within their communities; 2) the levels of social capital within U.S. communities appear to be on the decline, even as our population continues to age (2).

In this paper, we discuss the implications of the longterm trends in social capital for successful aging in U.S. society, as well as potential solutions for "building" social capital in the community, specifically through examples of options for senior housing. First, we turn to a case study that illustrates the relevance of social capital for the wellbeing of the elderly.

\section{A Case Study}

The July 1995 Chicago heat wave dramatically illustrates the relevance of social capital for the well-being of the elderly. This heat wave resulted in more than 700 deaths. As the sociologist Eric Klinenberg has pointed out, the pattern of deaths was not random (3). Three quarters of the heat-related deaths occurred among residents older than 65 years of age. The highest risk for death was concentrated among socially isolated elderly persons. From a case-control study of heat-related deaths, Semenza and colleagues (4) estimated that the odds ratio of dying during the heat wave was 2.3 (95\% CI, 1.4 to 3.5) among those living alone, whereas those who participated in community groups (such as clubs, churches, and support groups) experienced a 30\% lower risk for death (odds ratio, 0.7 [CI, 0.5 to 0.9$])$.

The underlying social conditions that led to the tragedy in Chicago in fact mirror broader trends in U.S. society. In Chicago, as well as in the rest of the United States, the proportion of persons who live alone has increased dramatically in the past four decades. According to the Census Bureau, the total number of Americans living alone rose from 10.9 million in 1970 to 24.9 million by 1996 (3). Approximately 1 of every 3 noninstitutionalized seniors now lives alone (5). For these 10 million older Americans, living alone increases vulnerability to a variety of threats to successful aging, including social isolation, financial insecurity, lack of stimulating interactions, and loss of mobility and transportation. Access to social capital within the broader community, derived through norms of mutual assistance between neighbors and the involvement of local groups, becomes important for this large group of elderly persons who have limited opportunity for social engagement within their homes. 
In the 1995 Chicago heat wave, the risk for dying was increased not just among personally isolated elderly persons. Death rates were especially high among those who resided in communities characterized by low levels of social interaction in public places and high crime rates (3). The absence of an active community life, combined with a fear of crime, kept many elderly persons locked inside their homes and prevented them from reaching community cooling centers during the heat wave crisis (3). As a result, the geographic pattern of heat wave deaths across Chicago neighborhoods was not random. Communities with an active street life, where neighbors saw each other and interacted on a daily basis, were more successful at protecting their residents against the risk of death. During the heat wave, these neighborhoods drew out even those individuals who were isolated and reclusive. This example illustrates the importance of the collective (or community) dimension of social capital, above and beyond the private benefits from interactions that individuals secure through their intimate relationships or social networks. According to some, the community stocks of social capital appear to be declining in U.S. society.

\section{The Decline of Social Capital in the United States}

In his 1995 essay "Bowling Alone" (6) and a subsequent book with the same title (2), the political scientist Robert Putnam argued that social capital in U.S. society has eroded. Whether measured in terms of formal membership and participation in civic organizations, informal socializing between neighbors, levels of trust between citizens, or indicators of voluntarism and charitable giving, social capital has declined sharply in this country since the mid-1960s.

According to Putnam, the long-term decline in civic engagement represents a generational (or birth cohort) effect, not an age effect. The so-called long civic generation-the cohort of citizens who attended school during the Great Depression and lived through World War IIhave maintained high levels of civic participation, community involvement, and social trust throughout their lives (2). As this generation has become an increasingly smaller part of the U.S. population, social capital has declined because subsequent generations have not maintained the same level of civic engagement. Americans born in the 1920 s are much more likely than those born in the 1960s to belong to an organization, to trust other people, to vote, to attend church, or to volunteer on a community project, all examples of activities that are critical to the maintenance of community social capital. Even as the "long civic generation" declines in size, they make up a progressively higher proportion of community members who hold together the social fabric. For example, while those 60 years of age or older made up $20 \%$ of community volunteers and $24 \%$ of club attendees in 1970 , these proportions increased to $35 \%$ and $38 \%$ in the 1990 s (2).
Some critics have contested Putnam's diagnosis, arguing that old forms of social capital have been replaced by new forms, such as the Internet $(7,8)$. In addition, the contention that cohorts born after 1960 differ from those born in the 1920s and 1930s cannot be fully evaluated until the later-born cohort reaches the same age and stage of the lifecourse. For cohorts born after the 1960s, civic engagement, volunteering, and other forms of "vital involvement" in the community may still catch up over time, as this group reaches late adulthood, retirement, and beyond.

Nonetheless, the long-term trends in U.S. society are of potential concern because the elderly today are not only the primary producers of the social glue that holds together communities, but they (and future generations of elders) are also significant beneficiaries of social capital. The role of communities in supporting the elderly is changing. Through reductions in Medicare and Medicaid funding for the institutional care for the elderly, the federal government has been pursuing a long-term policy of de-institutionalization for the elderly (9). From 1985 to 1995, the number of individuals age 65 to 74 years in the United States living in a nursing home fell from 12.5 persons per 1000 to 10.1 per 1000 . Among Americans age 85 years and older, the number of nursing home residents fell from 219 per 1000 to 199 per 1000 over the same period. These trends, coupled with the improved health and reduced functional impairment of today's older population, are mirrored by the rise in community-dwelling elders who are living alone. In turn, families and communities have been called on to assume a greater role as informal caregivers, even at a time when people are working longer hours (10). Home care, for which Medicare and Medicaid raised expenditures by 10-fold and 5-fold between 1987 and 1995, respectively (11), can aid informal caregivers but is not sufficient to satisfy all of the needs of those aging at home, including the need for vital social involvement. Our community social capital is declining at precisely the moment when it may be most needed.

\section{The Past and Future of Social Capital}

Proponents of social capital have sometimes been criticized for seeming to advocate turning back the clock on U.S. society to a bygone era when communities were more cohesive and people happily volunteered in community groups and the local church soup kitchen. Social capital, however, is neither a panacea for public health nor a concept that can be easily translated into a recipe for successful aging. In fact, "building" social capital has both positive and negative aspects, as we describe in the following section, specifically through a discussion of recent trends in senior housing options. Some types of housing environments almost enforce isolation, while other types facilitate interaction among elderly residents as well as foster connections between residents and the broader community. 
Although we do not purport to provide a comprehensive review of available living arrangements for the elderly, we highlight ways in which architecture and urban design may stimulate or deter future investment in social capital.

\section{Gated Communities: A Reaction to Decline in Social Capital?}

In the United States, gated and guarded communities have proliferated rapidly (12). These privately managed residential arrangements, which originated with retirement communities in southern Florida and California, are surrounded by walls that contain "entire neighborhoods, comprising homes, community infrastructure, services, and micro-urban governance" (13). The concept holds broad appeal to the U.S. public, especially among older people. In one survey, $42 \%$ of people older than 55 years of age favorably rated properties with gates and security (14). These communities were almost unknown in the 1970s, but by 1997 they housed up to 9 million residents in approximately 20000 communities (15). The Community Association Institute estimates that approximately $50 \%$ of all new homes in major metropolitan areas are within private community associations (13). Gated communities are marketed as loci of "security, neighborliness, social peers, social and age similarity, friendship ties, social networking, common values, group participation, and a sense of belonging" (16). Such marketing has been called the "commodification of community" (17). In other words, gated communities seemingly promise to recreate the social cohesion and social capital that have eroded elsewhere in U.S. society.

Whether gated communities deliver on their promise is another matter. Although few data with which to evaluate this issue empirically are available, preliminary indications suggest that gates and guards guarantee neither safety nor improved community integration for residents. In their book Fortress America, Blakely and Snyder conclude that "Gated communities are no better or worse than society as a whole in producing a strong sense of collective citizenship" (15). Furthermore, the walls and rules of gated communities may serve as agents of social control- defining who is and is not welcome (in terms of age, race, and certainly socioeconomic status), and codifying or asserting narrowly bound cultural and behavioral expectations. Nonetheless, gated living offers several potentially healthenhancing features: common spaces for gathering, sport, and play (clubhouses, swimming pools, golf courses); relatively low-traffic streets; and opportunities for involvement in community boards. These features may be viewed as facilitators of social interaction and social cohesion, but only within the confines of the community's walls.

What are the implications of gated communities for civic life outside the walls? As gated communities continue to multiply, they draw younger, wealthier retirees out of metropolitan centers, leaving older, poorer elderly residents behind, as well as a weakened tax base within urban areas
(18). In addition, this pattern of migration may deplete inner-city resources for civic involvement and reduce elderly persons' use of urban parks and cultural institutions. The problem peaks when gated communities threaten to secede from surrounding municipalities in favor of selfgovernance. The result is an exacerbation of social exclusion and political isolation of the "have nots." Those residents remaining in urban centers may be least likely to have the resources necessary to organize and lobby for much-needed services and amenities, such as community centers, transportation, street lighting, police or emergency response, and cleaning of public parks (19).

Especially in geographic regions saturated with gated communities, there is a need to examine trends in the health, well-being, political power, and social integration of elders within — and especially outside-the confines of gated America.

\section{Individualism or Institutionalization: Norms for U.S. Seniors?}

While gated communities are marketed as fonts of social interaction, the desire for individualism and independence remains strong among older Americans. According to an American Association of Retired Persons (AARP) survey of civic involvement, 59\% of 1500 adults older than 50 years of age agreed with the statement "I hate to depend on other people." In another survey by the AARP, $81 \%$ of respondents older than age 50 years preferred to remain in their current homes, and 64\% were confident that they could do so, even in the event of disabling illness (20). Only $4.5 \%$ (1.56 million) of U.S. elders currently reside in nursing homes, although risk for nursing home placement is higher among those living alone (21).

The institutional model of nursing home care remains in many ways the epitome of social isolation for elders, as homes are often geographically segregated from vital community centers (because of zoning laws), highly regulated, and depersonalized. Nursing homes and their care delivery systems are designed to maximize efficiency and safety, often at the expense of residents' quality of life. Bathrooms and showers may be centralized to facilitate staff support of residents' personal care, even though residents could benefit from performing activities of daily living in the privacy of their own rooms, thereby remaining as independent as possible for as long as possible (22). Institutions offer few private areas for congregation, minimizing opportunities for meaningful interaction among residents as well as between residents and their visitors. Finally, the health care delivery model in most traditional nursing homes defines residents as "patients" and leaves little room for families to participate in continued caregiving. As Regnier (22) put it, once an elderly person becomes a patient "the baton is passed," and care becomes the dominion of health care workers alone. With this institutional model, elders are effectively isolated both socially and geographically from their families and communities of origin. The pattern of 
declining nursing home use might therefore be argued as a positive trend in terms of putting elders back in touch with their families and communities. While this may be the case for elders who have families and communities to fall back on, it is unlikely to be true for those who lack such ties.

\section{Planned Care Environments}

Wolinsky and colleagues (23) have remarked on a shift in the nursing home market toward models that may promote more successful aging. This shift is represented by the increasing presence of "vertically integrated" housing options. Such communities link nursing homes to a continuum of retirement apartments, intermediate care, and skilled nursing facilities. These new residential options may presage a rehabilitation of the stereotype of the nursing home as a "total institution," with potentially beneficial effects on residents' autonomy and health outcomes.

For example, Homestead Village in Lancaster, Pennsylvania, was designed to promote reciprocal, intergenerational exchange between elderly residents and members of the surrounding community. The physical environment was planned accordingly to support residents' continued community connections and social engagement. Homestead Village was built on land originally owned by, and surrounding, the Church of the Apostles United Church of Christ. Church membership is not a requirement for residence at Homestead, but member-residents can continue to participate in church functions with ease because of proximity and church outreach. The planners of Homestead Village also provided onsite office facilities for voluntary organizations, such as the American Cancer Society and the American Heart Association, to facilitate residents' participation in volunteerism. Residents also volunteer at an onsite rehabilitation center, at the church's preschool program, and at nearby Lancaster General Hospital. Further resources include an indoor pool and walking track in a barn-like setting, as well as a chapel, medical care facilities, and common areas for fellowship. Homestead's planners also incorporated varied residence styles-single-family homes, townhouses, elevator apartments, skillednursing rooms - to accommodate residents' varying preferences and abilities. Residents may remain a part of the Homestead community even as their health care needs change.

\section{Assisted-Living Developments}

A major goal of assisted-living developments, which are now home to between 600000 and 1 million (mostly middle- and upper-income) U.S. elderly persons, is to shift from an institutional, medically based housing model to a residential, therapeutic one. While the definitions and classifications for assisted living vary, in general these developments provide independent, residential living with some personal and health-related assistance. Designed especially for elderly individuals who might be socially isolated, these facilities attempt to create a community with both mental and physical stimulation. The facilities are often designed to foster social interaction and social connections $(24,25)$.

In an assisted-living facility in northeast Illinois, for example, the developers applied a home/household/neighborhood/village structure to promote a communal atmosphere (26). Rather than maintaining the traditional model with many apartments and a central dining area, wings of the home were designed to serve as "neighborhoods" with units facing an internal "street." Activity centers with a bathing room, craft room, and other areas flanked the "street" to offer opportunities for spontaneous social interaction. For every 4 to 6 apartments - each with its own bedroom, living rooms, and kitchens—small lounge areas were made available to serve small-scale interactions between immediate neighbors. Shared spaces for all residents were also built, including a greenhouse, coffee shop, dining area, and kitchen.

However, as in the case of nursing homes, U.S. zoning regulations often result in the geographical isolation of assisted-living facilities, thereby thwarting the goal of community integration. In addition, because of the lack of federal regulation, assisted-living options may be illequipped to provide skilled-nursing services for the most dependent elders.

The most promising models of assisted living attempt to integrate these facilities with their surrounding communities. Regnier (24) offers several such models from northern Europe, where senior residences coexist in neighborhoods with schools, community centers, businesses and retail shops, and parks. Instead of removing elders from vital community hubs, these homes are centered in, and contribute to, areas dense with social activity. For example, in the Jan van der Ploeg development in urban Rotterdam, the Netherlands, planning decisions involved local community members, while elderly volunteers within the development manage an onsite grocery store and restaurant. The Flesseman Center in Amsterdam overlooks a busy subway station, providing proximity that is both practical and entertaining for residents with limited mobility. In Finland, the Old People's Home and Health Center of Oitti was constructed over a busy pedestrian thoroughfare that connects two parts of town; this traffic can be viewed from the center's dining room. At the Kuuselan Palvelukoti project in Finland, the swimming pool, restaurant, and sauna are open to elderly residents and neighbors of the project. And at the de Klinker and de Gooyer elder housing project in Amsterdam, the billiards bar was designed to resemble a neighborhood café. The bar became so popular with locals of all ages that the staff began to screen visitors by age to optimize use by patrons older than 65 years of age (all examples from Regnier [24]). These models, designed to structurally facilitate continued social involvement by elders, provide a sharp contrast to the geographic and social isolation that often accompany moves to assistedliving facilities out of the community mainstream in the United States. 


\section{CONCLUSION}

Social capital is an important ingredient for successful aging. The elderly are represented on both the supply and demand sides of social capital within the community. Social capital-at least in the form of civic engagement, neighborliness, and generalized trust-is on the decline in U.S. society.

Clinicians can harness the benefits of social capital in several ways. For example, they should incorporate an assessment of the community living situations of elderly patients into routine clinical assessment and care. In certain cases, it would be appropriate for clinicians to prescribe more active involvement of patients in their communities (for example, through volunteering in local services or involvement in senior centers), just as they would currently prescribe regular exercise or smoking cessation. Gerontologists can become active advocates for long-term housing options that emphasize greater integration into local communities. Like any public good, however, the provision of social capital is likely to require coordinated planning and financing (for example, in the form of subsidies for assistedliving developments) at the federal, state, and local levels.

Although there is no simple solution to rebuilding lost social capital, emerging developments in elder housing options offer the potential for translating social capital into health gains. While existing elder housing options must be carefully evaluated and future residences thoughtfully planned, in truth many of the nation's elderly will "age in place," creating "naturally occurring retirement communities." Will these communities successfully keep up with the changing needs of an aging population? The answer to that question depends on our investments in social capital today.

From Merck Research Laboratories, Blue Bell, Pennsylvania; Tulane University School of Medicine, New Orleans, Louisiana; and Harvard School of Public Health, Boston, Massachusetts.

Potential Financial Conflicts of Interest: None disclosed.

Requests for Single Reprints: Ichiro Kawachi, MD, PhD, Harvard School of Public Health, 677 Huntington Avenue, Boston, MA 02115.

\section{References}

1. Kawachi I, Berkman LF. Social cohesion, social capital, and health. In: LF Berkman, Kawachi I, eds. Social Epidemiology. New York: Oxford Univ Pr; 2000:174-90.
2. Putnam RD. Bowling Alone. The Collapse and Revival of American Community. New York: Simon \& Schuster; 2001.

3. Klinenberg E. Heat Wave. A Social Autopsy of Disaster in Chicago. Chicago: Univ of Chicago Pr; 2002.

4. Semenza JC, Rubin CH, Falter KH, Selanikio JD, Flanders WD, Howe HL, et al. Heat-related deaths during the July 1995 heat wave in Chicago. N Engl J Med. 1996;335:84-90. [PMID: 8649494]

5. Hetzel L, Smith A. The 65 years and Over Population. United States 2000 Census. Brief, C2KBR/01-10. Washington, DC: U.S. Census Bureau; 2001.

6. Putnam RD. Bowling alone: America's declining social capital. Journal of Democracy. 1995;6:65-78.

7. Hall JA, Lindholm C. Is America Breaking Apart? Princeton, NJ: Princeton Univ Pr; 1999.

8. Wuthnow R. Loose Connections. Cambridge, MA: Harvard Univ Pr; 1998. 9. Jacobzone S. Coping with aging: international challenges. Health Aff (Millwood). 2000;19:213-25. [PMID: 10812801]

10. Schor JB. The Overworked American. The Unexpected Decline of Leisure. New York: BasicBooks; 1991.

11. Kenney G, Rajan S, Soscia S. State spending for Medicare and Medicaid home care programs. Health Aff (Millwood). 1998;17:201-12. [PMID: 9455033]

12. Harris JC, Evans JS. Suburban fortresses. Tierra Grande: Journal of the Real Estate Center at Texas A \& M University. 1999;6:1.

13. Webster C, Glasze G, Frantz K. The global spread of gated communities. Environment and Planning B: Planning and Design. 2002;29:315-20.

14. Emrath P. Neighborhood crime: reality and perceptions. Home Economics. $1998 ;: 10-3$.

15. Blakely E, Snyder M. Fortress America. Gated communities in the United States. Washington, DC: Brookings Institution Pr; 1997.

16. Townshend I. Age segregated and gated retirement communities in the 3rd age: the differential contribution of place-community to self-actualization. Environment and Planning B: Planning and Design. 2002;29:371-96.

17. Fry C. The community as a commodity: the age-graded case. Human Organization. 1977;36:115-23.

18. Clark WA, Davies S. Elderly mobility and mobility outcomes: households in the later stage of the life course. Res Aging. 1990;12:430-62. [PMID: 2277857]

19. Kawachi I, Kennedy BP. The social costs of consumption. The Health of Nations. New York: New Pr; 2002:137-59.

20. Harney, KR. The nation's housing: seniors want to stay put, survey shows. Los Angeles Times. 1996;10 November:K1-2.

21. Kane RA, Kane RL. Long-Term Care: Principles, Programs, and Policies. New York: Springer; 1997.

22. Regnier V. In: Willis SL, Schaie KW, Hayward M, eds. Societal Mechanisms for Maintaining Competence in Old Age. New York: Springer; 1997:232-50.

23. Wolinsky FD, Stump TE, Callahan CM. In: Willis SL, Schaie KW, Hayward M, eds. Societal Mechanisms for Maintaining Competence in Old Age. New York: Springer; 1997:94-130.

24. Regnier V. Assisted Living Housing for the Elderly: Design Innovations from the United States and Europe. New York: Van Nostrand Reinhold; 1994.

25. Regnier V, Hamilton J, Yatabe S. Assisted Living for the Aged and Frail: Innovations in Design, Management, and Financing. New York: Columbia Univ Pr; 1995.

26. Cinelli D. Place makes a difference: a case study in assisted living. In: Schwartz B, Brent R, eds. Aging, Autonomy, and Architecture: Advances in Assisted Living. Baltimore: Johns Hopkins Univ Pr; 1999. 
Current Author Addresses: Dr. Cannuscio: Epidemiology Department, Merck Research Laboratories, 10 Sentry Parkway BL 1-7, Blue Bell, PA 19422.
Dr. Block: 727 1/2 Henry Clay, New Orleans, LA 70118.

Dr. Kawachi: Department of Health and Social Behavior, Harvard School of Public Health, 677 Huntington Avenue, Boston, MA 02115. 